\title{
The role of a defunctioning stoma for colonic and perianal Crohns disease in the biological era
}

M. Marti-Gallostra, Pär Myrelid, N. Mortensen, S. Keshav, S. P. L. Travis and B. George

\author{
Journal Article
}

\section{Tweet}

N.B.: When citing this work, cite the original article.

This is an electronic version of an article published in:

M. Marti-Gallostra, Pär Myrelid, N. Mortensen, S. Keshav, S. P. L. Travis and B. George, The role of a defunctioning stoma for colonic and perianal Crohns disease in the biological era, Scandinavian Journal of Gastroenterology, 2017. 52(3), pp.251-256.

Scandinavian Journal of Gastroenterology is available online at informaworldTM: http://dx.doi.org/10.1080/00365521.2016.1205127

Copyright: Taylor \& Francis: STM, Behavioural Science and Public Health Titles http://www.tandf.co.uk/journals/default.asp

Postprint available at: Linköping University Electronic Press

http://urn.kb.se/resolve?urn=urn:nbn:se:liu:diva-134778

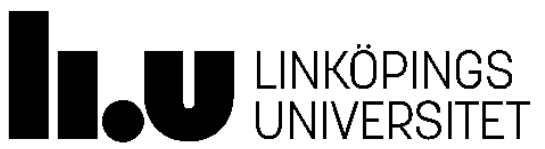




\title{
The role of a defunctioning stoma for colonic and perianal Crohn's disease in the biological era
}

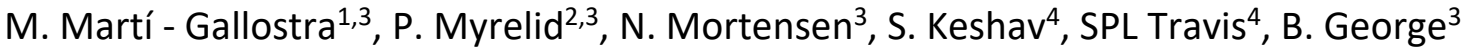 \\ ${ }^{1}$ Unit of Colorectal Surgery, Department of General Surgery, Hospital Universitari Vall Hebrón, \\ Barcelona, Spain, \\ ${ }^{2}$ Division of Surgery, Department of Clinical and Experimental Medicine, Faculty of Health Sciences, \\ Linköping University, and Department of Surgery, County Council of Östergötland, Linköping, \\ Sweden, \\ ${ }^{3}$ Department of Surgery, Unit of Colorectal Surgery, Oxford University Hospitals, \\ Oxford, UK, \\ ${ }^{4}$ Translational Gastroenterology Unit, Oxford University Hospitals, Oxford, UK. \\ Correspondence: \\ Bruce George \\ Department of Surgery, Unit of Colorectal Surgery, Oxford University Hospitals, \\ Old Road, Headington \\ Oxford OX3 7LE \\ United Kingdom \\ Email: brucegeorge@doctors.org.uk
}

Word Account: 2195

Running title: De-functioning still has a value.

M. Martí - Gallostra and P. Myrelid contributed equally to the preparation of the manuscript. 


\section{Abstract}

Objective

A defunctioning stoma is a therapeutic option for colonic or perianal Crohn's disease. In the pre-biologic era the response rate to defunctioning in our unit was high (86\%) but intestinal continuity was only restored in $11-20 \%$. Few data exist on the outcome of defunctioning since the widespread introduction of biologicals.

Material and Methods

All patients undergoing a defunctioning stoma for colonic/perianal Crohn's disease

2003-2011 were identified from a prospective database. Indications for surgery, medical therapy, response to defunctioning and long-term clinical outcome were recorded. Successful restoration of continuity was defined as no stoma at last follow up.

Results

76 patients were defunctioned (57 with biologicals) and at last follow up, 20 (27\%) had continuity restored. Early clinical response rate (<3 months) was 15/76 (20\%) and overall response $31 / 76$ (41\%). Complex anal fistulae/stenosis were associated with a very low chance of restoring continuity ( $10 \%$ and $0 \%$ respectively) while colitis was associated with a higher chance of restoring continuity (48\%). Endoscopic or histological improvement in colitis after defunctioning was associated with a higher rate of restoring continuity $(10 / 16$, $63 \%)$ compared to no such improvement $(4 / 15,27 \%, p=0.05)$. Those failing biologics had similar chance of restoration as those not receiving biologics, 15/57 (26\%) and 5/19 (26\%) respectively.

Conclusion

Overall response to colonic defunctioning was $41 \%$. Successful restoration of continuity occurred in $27 \%$, but $48 \%$ in the absence of perianal disease. Response is appreciably less 
than in the pre-biologic era, so patient and physician expectations need to be managed appropriately. 


\section{Introduction}

The management of colonic and perianal Crohn's disease refractory to medical therapy is challenging as patients are understandably keen to avoid a permanent stoma [1]. Colonic disease with ano-rectal sparing may be managed by segmental or total colectomy. Fistulising anal Crohn's disease may be treated with fistulotomy [2], loose seton drainage[3] and advancement flaps[4]. The advent of medical therapy with infliximab[5] and adalimumab[6] has dramatically changed management algorithms for patients with large bowel and perianal Crohn's disease[7]. Increasingly combinations of medical and surgical approaches are being adopted with improved outcomes [8-11].

The place of a defunctioning stoma without colonic resection in the management of Crohn's colitis ( $c C D$ ) or perianal Crohn's disease $(p C D)$ is controversial. Reports from Canada and US, prior to the widespread use of biologicals, reported response rates of up to $95 \%[12,13]$ while our own institution reported an $86 \%$ early response [14]. The chance of subsequent long-term restoration of gastrointestinal continuity however is low, $20 \%$ (11/55) for Crohn's colitis and $11 \%(2 / 18)$ for perianal disease.

Biological therapy (adalimumab or infliximab) has revolutionised medical management of luminal as well as perianal Crohn's disease[15]. Nevertheless, biological therapy is often unsuccessful in $C C D$ or $p C D$ and there are almost no data on the outcomes of a defunctioning stoma after failure of biological therapy. Our aim was to assess the impact of a defunctioning stoma for both peri-anal and colonic Crohn's disease in the biological era. 


\section{Methods}

All patients at Oxford University Hospitals undergoing a defunctioning stoma for CCD and pCD between 2003 and 2011 were identified from a prospective surgical database. Patients undergoing simultaneous intestinal resection were excluded.

The following information was recorded from the database and confirmed/ or clarified if necessary by review of patient notes:

Pre-defunctioning: demographics, duration of Crohn's disease, medical therapy and dominant indication for surgery.

Operative details: type of defunctioning stoma and any associated surgery.

Post-operative: early complications of stoma formation (within 30 days), late complications of stoma formation (during follow up), response to defunctioning, colonoscopy findings and associated pathology reports, subsequent surgery and long-term outcomes. The primary outcome of interest was restoration of intestinal continuity at last follow up.

\section{Definitions}

Early and late response to defunctioning: response was defined as a reduction in gastrointestinal symptoms and improvement in general well-being according to the patient notes and reduction in inflammatory markers. Early response was defined as within 3 months of the defunctioning stoma. Late response was defined as after 3 months. Successful restoration of intestinal continuity was defined as reversal of diverting ostomy. Endoscopic response was evaluated by the endoscopist's subjective report; no formal scoring was used. 
Histological disease activity in mucosal biopsies at colonoscopy pre-defunctioning and postdefunctioning, where response was defined as improvement in the endoscopic grade of activity (severe/moderate/mild/quiescent) assessed by a specialist gastrointestinal pathologist.

Simple fistulae: subcutaneous, inter-sphincteric or low tran-sphinctric fistula with single tracts or inflammatory changes.

Complex fistulae: supra-levator fistula tract, multiple tracts, or ano-vaginal fistulae.

\section{$\underline{\text { Statistics }}$}

Results are expressed as median and range for non-parametric data. Groups were compared using 2-tailed Fisher's exact test. Stata 13 (StataCorp, TX, USA) was used for statistical analysis. 


\section{Results}

76 patients underwent a defunctioning stoma (median age 34 years, range 12-85, 42 female and 34 male. Demographic details, disease duration and indications for defunctioning are shown in table $1.57 / 76(75 \%)$ patients were on biological therapy prior to the defunctioning stoma. Of these 18/57 (32\%) received adalimumab and 39/57 (68\%) infliximab; 5 had received both. 40 (53\%) patients also received immunomodulators, The primary reason for not receiving biological therapy was uncontrolled perianal sepsis ( $n=12 / 76,63 \%)$.

\section{Operative details}

62/76 (82\%) patients underwent an ileostomy (54 loop ileostomy, 8 end ileostomy, 31/62 laparoscopic procedure); 14 (18\%) underwent a loop colostomy (5 laparoscopic procedure). All patients with perianal disease had a simultaneous examination under anaesthetic (EUA). 11/54 with perianal disease underwent seton drain insertion, 3 recto vaginal fistula (RVF) repair and 1 advancement flap repair of a high anal fistula.

\section{Post-operative outcome}

The early response to defunctioning was 15/76 (20\%). A further 16 patients responded after 3 months, giving an overall response rate of $31 / 76$ (41\%). Response rate by indication are shown in table 2.

Early and late response rates did not differ between patients receiving biologics and those who did not (early response $13 / 57$ on biologics, $2 / 19$ not on biologics, $p=0.41$; late response $11 / 57$ on biologics, $5 / 19$ not on biologics, $p=0.72$ ). 
Colonoscopy or flexible sigmoidoscopy was undertaken after defunctioning in 19/31 (61\%) patients with CCD. 8/19 (42\%) had endoscopic and/or pathological evidence of reduced inflammation. $11 / 19(58 \%)$ had no improvement in severity of inflammation either endoscopically or pathologically after defunctioning.

\section{Long-term outcome}

Patients were followed up for a median 48 months (range 12-107). 2/76 (3\%) patients were lost to follow-up, both in the group treated with biologicals. Overall $24 / 74$ (32\%) patients had the stoma reversed after a median of 16 months (range 3-75), although 4/24 (17\%) had to have the stoma re-fashioned later because of poor function or disease recurrence. At last follow-up, 20/74 patients had intestinal continuity restored (27\%) with similar outcomes between those not on biologics, 5/19 (26\%), as those receiving biologics in combination with diversion, $15 / 55$ (27\%). The outcome according to the indication for stoma is shown in Table 3 and the time until restoration of the gastrointestinal continuity in Figure 3.

Patients with colitis +/- perianal disease: At long term follow-up of the 29 patients with colitis (21 no anal disease, 8 with anal disease), 13(45\%) achieved restoration of gastrointestinal continiuty. Seven of the $13(54 \%)$ underwent segmental or total colectomy prior to restoration of continuity. 1 patient had the diagnosis revised from Crohn's to UC and subsequently underwent ileo-anal pouch reconstruction. Of the 31 patients with colitis (with or without peri-anal disease), an endoscopic and/or histological improvement was seen in $16 / 29(52 \%)$ patients after defunctioning. Of these 10 (63\%) ultimately achieved GI continuity and 4 (25\%) did not ( 2 patients lost to follow-up). Of the other 15 (48 \%) in whom 
endoscopic or histological improvement was not observed only 4 (27\%) achieved GI continuity ( $p=0.03,2$ tailed Fishers exact: 10 of 14 vs 4 of 15$)$.

Rectovaginal fistula: Of the 8 patients in whom the dominant indication for diversion was a rectovaginal fistula, 4 (50\%) achieved restoration of continuity. Three had undergone surgical repair of the fistula and one healed without local repair.

Ano-rectal stricture: None of the 6 patients in whom the dominant indication for surgery was an ano-rectal stricture achieved restoration of continuity.

Proctectomy or permanent diversion: 35/74 (46\%) patients have undergone proctocolectomy/proctectomy with permanent stoma formation and 19/74 (25\%) patients remain "indefinitely diverted". In one patient who underwent proctectomy 3 years after defunctioning for severe perianal disease, histological examination of the specimen revealed rectal adenocarcinoma. This had not been anticipated pre-operatively.

Complications related to stoma formation: 18 patients developed a complication related to the defunctionjng stoma (table 4). The most common complication was a parastomal hernia. Two patients required re-operation for stoma related complications, one for early small bowel obstruction and one for an anastomotic leakage following stoma closure. 


\section{Discussion}

The major finding of this study was that the dominant indication for a defunctioning stoma is highly predictive of the likelihood of subsequent restoration of gastrointestinal continuity. Overall, $27 \%$ of patients in this study achieved restoration of GI continuity after a defunctioning stoma. This figure is similar to previous studies. However the new observation from this study is that the outcome varies dramatically depending on the dominant indication for defunctioning.

No patient with ano-rectal stricturing and very few with complex anal fistulating disease achieved restoration of GI continuity. This has implications for counselling patients who are considering a defunctioning stoma. If complex fistulae or anorectal stricturing are present then the patient should understand that the prospects of future reversal are minimal and the procedure should be viewed as a "stepping stone" to proctectomy and permanent stoma.

Patients with Crohn's colitis had a much better chance of stoma closure, especially in the absence of perianal disease. For patients with cCD, endoscopic appearance and/or histological evidence of a reduction in mucosal inflammation was associated with a better chance of stoma reversal. Patients are best counselled that a decision regarding future stoma reversal will involve careful assessment of the response to defunctioning by endoscopy and biopsy. In our study colonoscopic/flexible sigmoidoscopy was typically undertaken 6-9 months post diversion. Pathological assessment of the defunctioned colon and rectum in Crohn's disease is difficult, since defunctioned changes may mimic Crohn's disease[10] . In this study a reduction in endoscopic and histological inflammation was 
associated with an improved chance of stoma reversal. Challenging the defunctioned colon by instilling ileostomy effluent down the efferent limb of a loop ileostomy has been attempted to predict the behaviour of the colon following stoma reversal, but has never gained widespread acceptance. It is interesting to speculate that this technique may yet present an experimental model to test novel therapy before re-anastomosis, since relapse often occurs rapidly after instillation whether measured by symptoms, biochemical (CRP), or endoscopic criteria.

A second important finding of this study was that the acute response to defunctioning was only $20 \%$ ( $23 \%$ in those receiving biologics pre-op) and the overall (acute + late) response $41 \%$ ( $25 \%$ in those receiving biologics). This is notably lower than in all studies reported in the pre-biologics era $[2,3,13,14,16]$, where the range of response was $81-91 \%$ One explanation for this difference may be that anti-TNF therapy has already achieved a maximum reduction of colonic or perianal inflammation and that the addition of a defunctioning stoma achieves little further reduction in inflammation. An alternative explanation is that the beneficial effects of biologicals mean that only patients with the most severe and intractable disease now come to surgery[17-20]. Coscia et al [21] recently found an important reduction of the risk for a permanent stoma in patients with extensive Crohn's colitis due to the biological use after subtotal colectomy. Nevertheless all these patients were excluded in our series.

Despite these modest outcomes, an appreciable proportion of patients are content with their stoma after defunctioning, realising that reversal is not an option, but nevertheless do not wish to undergo proctectomy/proctocolectomy. The risks of proctectomy /proctocolectomy must be balanced against the small but catastrophic risk of malignancy 
developing in the defunctioned colon or anorectum. One patient in our series was unexpectedly found to have adenocarcinoma in the defunctioned rectum at the time of proctectomy only 3 years after diversion. Surveillance of the defunctioned colon and rectum is difficult due to diversion changes and reduced distensibility of the bowel, or even impossible due to stricturing. Our departmental policy has been to recommend resection in this situation unless the patient is elderly with significant co-morbidity.

This study confirms previous reports that most patients who require a defunctioning stoma for $\mathrm{pCD}$ or CCD ultimately end up with a permanent stoma[20] and that the response rate to defunctioning in the biological era is lower than reports before 2000, when biological therapy became widespread. Patients with complex anal fistulating disease or ano-rectal strictures have a particularly low chance of restoring GI continuity. Patients defunctioned for Crohn's colitis have a higher chance of restoring GI continuity which can be further predicted by colonoscopy and histological assessment of the diverted colon. Further, Spivak et al[22] identified antibodies to a microbial antigen (Pseudomonas fluorescens) to be strongly predictive of the clinical response to defunctioning.

These findings have useful implications when counselling patients about the option of a defunctioning stoma when medical therapy, including biologics, has failed. Nevertheless, despite these modest outcomes, de-functioning retains an important role for improving quality of life in patients suffering the devastating consequences of medically refractory perianal or colonic Crohn's disease. 


\section{REFERENCES}

1. Byrne CM, Solomon MJ, Young JM, Selby W, Harrison JD: Patient preferences between surgical and medical treatment in Crohn's disease. Dis Colon Rectum 2007, 50(5):586-597.

2. Williams JG, Rothenberger DA, Nemer FD, Goldberg SM: Fistula-in-ano in Crohn's disease. Results of aggressive surgical treatment. Dis Colon Rectum 1991, 34(5):378-384.

3. Scott HJ, Northover JM: Evaluation of surgery for perianal Crohn's fistulas. Dis Colon Rectum 1996, 39(9):1039-1043.

4. Makowiec F, Jehle EC, Becker HD, Starlinger M: Clinical course after transanal advancement flap repair of perianal fistula in patients with Crohn's disease. Br J Surg 1995, 82(5):603-606.

5. Present DH, Rutgeerts $P$, Targan S, Hanauer SB, Mayer L, van Hogezand RA et al: Infliximab for the treatment of fistulas in patients with Crohn's disease. N Engl J Med 1999, 340(18):1398-1405.

6. Colombel JF, Schwartz DA, Sandborn WJ, Kamm MA, D'Haens G, Rutgeerts P et al: Adalimumab for the treatment of fistulas in patients with Crohn's disease. Gut 2009, 58(7):940-948.

7. Van Assche G, Dignass A, Reinisch W, van der Woude CJ, Sturm A, De Vos M et al: The second European evidence-based Consensus on the diagnosis and management of Crohn's disease: Special situations. J Crohns Colitis 2010, 4(1):63-101.

8. Hyder SA, Travis SP, Jewell DP, Mc CMNJ, George BD: Fistulating anal Crohn's disease: results of combined surgical and infliximab treatment. Dis Colon Rectum 2006, 49(12):1837-1841.

9. Duff S, Sagar PM, Rao M, Dolling S, Sprakes M, Hamlin PJ: Infliximab and surgical treatment of complex anal Crohn's disease. Colorectal Dis 2012, 14(8):972-976.

10. Topstad DR, Panaccione R, Heine JA, Johnson DR, MacLean AR, Buie WD: Combined seton placement, infliximab infusion, and maintenance immunosuppressives improve healing rate in fistulizing anorectal Crohn's disease: a single center experience. Dis Colon Rectum 2003, 46(5):577-583.

11. Regueiro $M$, Mardini $\mathrm{H}$ : Treatment of perianal fistulizing Crohn's disease with infliximab alone or as an adjunct to exam under anesthesia with seton placement. Inflamm Bowel Dis 2003, 9(2):98-103.

12. Grant DR, Cohen Z, McLeod RS: Loop ileostomy for anorectal Crohn's disease. Can J Surg 1986, 29(1):32-35.

13. Yamamoto T, Allan RN, Keighley MR: Effect of fecal diversion alone on perianal Crohn's disease. World J Surg 2000, 24(10):1258-1262; discussion 1262-1253.

14. Edwards CM, George BD, Jewell DP, Warren BF, Mortensen NJ, Kettlewell MG: Role of a defunctioning stoma in the management of large bowel Crohn's disease. Br J Surg 2000, 87(8):1063-1066.

15. Behm BW, Bickston SJ: Tumor necrosis factor-alpha antibody for maintenance of remission in Crohn's disease. Cochrane Database Syst Rev 2008(1):CD006893.

16. Zelas P, Jagelman DG: Loop illeostomy in the management of Crohn's colitis in the debilitated patient. Ann Surg 1980, 191(2):164-168.

17. Lichtenstein GR, Yan S, Bala M, Blank M, Sands BE: Infliximab maintenance treatment reduces hospitalizations, surgeries, and procedures in fistulizing Crohn's disease.

Gastroenterology 2005, 128(4):862-869.

18. Sands BE, Anderson FH, Bernstein CN, Chey WY, Feagan BG, Fedorak RN et al: Infliximab maintenance therapy for fistulizing Crohn's disease. N Engl J Med 2004, 350(9):876-885.

19. Sands BE, Blank MA, Patel K, van Deventer SJ: Long-term treatment of rectovaginal fistulas in Crohn's disease: response to infliximab in the ACCENT II Study. Clin Gastroenterol Hepatol 2004, 2(10):912-920. 
20. Hong MK, Craig Lynch A, Bell S, Woods RJ, Keck JO, Johnston MJ et al: Faecal diversion in the management of perianal Crohn's disease. Colorectal Dis 2011, 13(2):171-176.

21. Coscia M, Gentilini L, Laureti S, Gionchetti P, Rizzello F, Campieri M et al: Risk of permanent stoma in extensive Crohn's colitis: the impact of biological drugs. Colorectal Dis 2013, 15(9):1115-1122.

22. Spivak J, Landers CJ, Vasiliauskas EA, Abreu MT, Dubinsky MC, Papadakis KA et al: Antibodies to 12 predict clinical response to fecal diversion in Crohn's disease. Inflamm Bowel Dis 2006, 12(12):1122-1130. 


\section{Tables}

\section{Table 1}

Demographic and indications for defunctioning stoma

\begin{tabular}{|c|c|c|c|}
\hline & $\begin{array}{c}\text { All defunctioned } \\
\text { patients } \\
n=76(100 \%)\end{array}$ & $\begin{array}{c}\text { Defunctioning } \\
\text { despite biological } \\
\text { therapy } \\
n=57(75 \%)\end{array}$ & $\begin{array}{c}\text { Defunctioning } \\
\text { without biological } \\
\text { therapy } \\
n=19(25 \%)\end{array}$ \\
\hline Age (years) & 34 (range 12-85) & 33 (range $12-85$ ) & 43 (range $22-85$ ) \\
\hline Gender (F/M) & $42 / 34$ & $32 / 25$ & $10 / 9$ \\
\hline $\begin{array}{l}\text { Disease duration } \\
\text { prior to } \\
\text { defunctioning } \\
\text { (years) }\end{array}$ & $7.0(0.1-32)$ & $7.1(0.2-32)$ & $6.7(0.1-29)$ \\
\hline $\begin{array}{l}\text { Concomitant } \\
\text { therapy with } \\
\text { immunomodulators }\end{array}$ & 40 (53 \%) & $34(60 \%)$ & $6(32 \%)$ \\
\hline Colitis only & $22(29 \%)$ & $16(28 \%)$ & $6(32 \%)$ \\
\hline $\begin{array}{l}\text { Colitis and perianal } \\
\text { involvement }\end{array}$ & $\begin{array}{l}\qquad 9(12 \%) \\
\text { (fissure 2, simple } \\
\text { fistula 4, complex } \\
\text { fistula 3) }\end{array}$ & $7(12 \%)$ & $2(10 \%)$ \\
\hline Ano-rectal stricture & $6(8 \%)$ & $3(5 \%)$ & $3(16 \%)$ \\
\hline $\begin{array}{l}\text { Fistulating anal } \\
\text { disease }\end{array}$ & $\begin{array}{c}39(51 \%) \\
\text { (complex 31, isolated } \\
\text { rectovaginal fistula } 8 \text { ) }\end{array}$ & $31(54 \%)$ & $8(42 \%)$ \\
\hline
\end{tabular}




\section{Table 2}

Clinical response rate by indication to a defunctioning stoma in perianal or colonic Crohn's disease in the biological era.

\begin{tabular}{|l|c|c|}
\hline Indication for stoma $(\mathrm{n}=76)$ & $\begin{array}{c}\text { Early response }(<3 \text { months) } \\
(\mathrm{n}=15 / 76)\end{array}$ & $\begin{array}{c}\text { Late response }(\geq 3 \text { months) } \\
(\mathrm{n}=16 / 76)\end{array}$ \\
\hline Colitis - peri-anal $(\mathrm{n}=22)$ & $6(27 \%)$ & $3(14 \%)$ \\
\hline Colitis + peri-anal $(\mathrm{n}=9)$ & $3(33 \%)$ & $5(56 \%)$ \\
\hline Stenosis $(\mathrm{n}=6)$ & $0(0 \%)$ & $1(17 \%)$ \\
\hline Fistulating $(\mathrm{n}=39)$ & $6(15 \%)$ & $7(18 \%)$ \\
\hline & & $16(21 \%)$ \\
\hline Total $\mathrm{n}=76$ & $15(20 \%)$ & \\
\hline
\end{tabular}




\section{Table 3}

Long term outcome according to the indication for defunctioning stoma in perianal and colonic Crohn's disease in the biological era.

\begin{tabular}{|l|c|c|}
\hline & $\begin{array}{c}\text { Permanent stoma } \\
n(\%)\end{array}$ & $\begin{array}{c}\text { Gl continuity } \\
n(\%)\end{array}$ \\
\hline Overall $(n=74)$ & $54(73 \%)$ & $20(27 \%)$ \\
\hline Colitis no anal disease $(n=21)^{*}$ & $11(52 \%)$ & $10(48 \%)$ \\
\hline Colitis and anal disease $(n=8)^{*}$ & $5(63 \%)$ & $3(38 \%)$ \\
\hline Anal stenosis $(n=6)$ & $6(100 \%)$ & $0(0 \%)$ \\
\hline $\begin{array}{l}\text { Complex peri-anal fistula } \\
(n=31)\end{array}$ & $28(90 \%)$ & $3(10 \%)$ \\
\hline Rectovaginal fistula $(n=8)$ & $4(50 \%)$ & $4(50 \%)$ \\
\hline
\end{tabular}

*Patient lost for long term follow up out of the original 76 patients, both in the group treated with biologicals. 


\section{Table 4}

Complications related to stoma formation.

\begin{tabular}{|l|c|}
\hline & $\begin{array}{c}\text { Stomas } \\
\mathrm{n}=76(\%)\end{array}$ \\
\hline Early obstruction & $3(4 \%)^{*}$ \\
\hline Peri-stomal hernia & $10(13 \%)$ \\
\hline Stricture & $1(1 \%)$ \\
\hline Peri-ileostomy fistula & $1(1 \%)$ \\
\hline Pyoderma gangrenosum & $2(3 \%)$ \\
\hline Leak after ileostomy reversal & $1(1 \%)^{*}$ \\
\hline
\end{tabular}

*Requiring reoperation in one case each 


\section{Legends to Figures}

\section{Figure 1}

Consort diagram of 76 patients with Crohn's disease going through diverting stoma mainly due to colonic $(n=38)$ or perianal $(n=57)$ Crohn's disease and the short-term (clinical improvement) and long-term outcome (long term restoration of bowel continuity).

\section{Fig $1 \mathrm{~A}$}

57 patients receiving biological treatment and defunctioning stoma

\section{Fig 1 B}

19 patients without biological therapy but with defunctioning stoma

\section{Figure 2}

Time with diverting stoma until closure in 76 patients with Crohn's colitis and or perianal disease. A total number of 24 (32\%) patients had their gastrointestinal continuity restored during the follow up.

\section{Figure 3}

Time until new diverting stoma and/or resectional surgery in 24 patients with Crohn's colitis and/or perianal disease who had their gastrointestinal continuity restored after diversion. A total number of $4(17 \%)$ patients needed a new diversion and/or resectional surgery leaving $20(27 \%)$ patients with long term restored gastrointestinal continuity out of the original 76 patients with treated with a diverting stoma. 
Fig 1 A

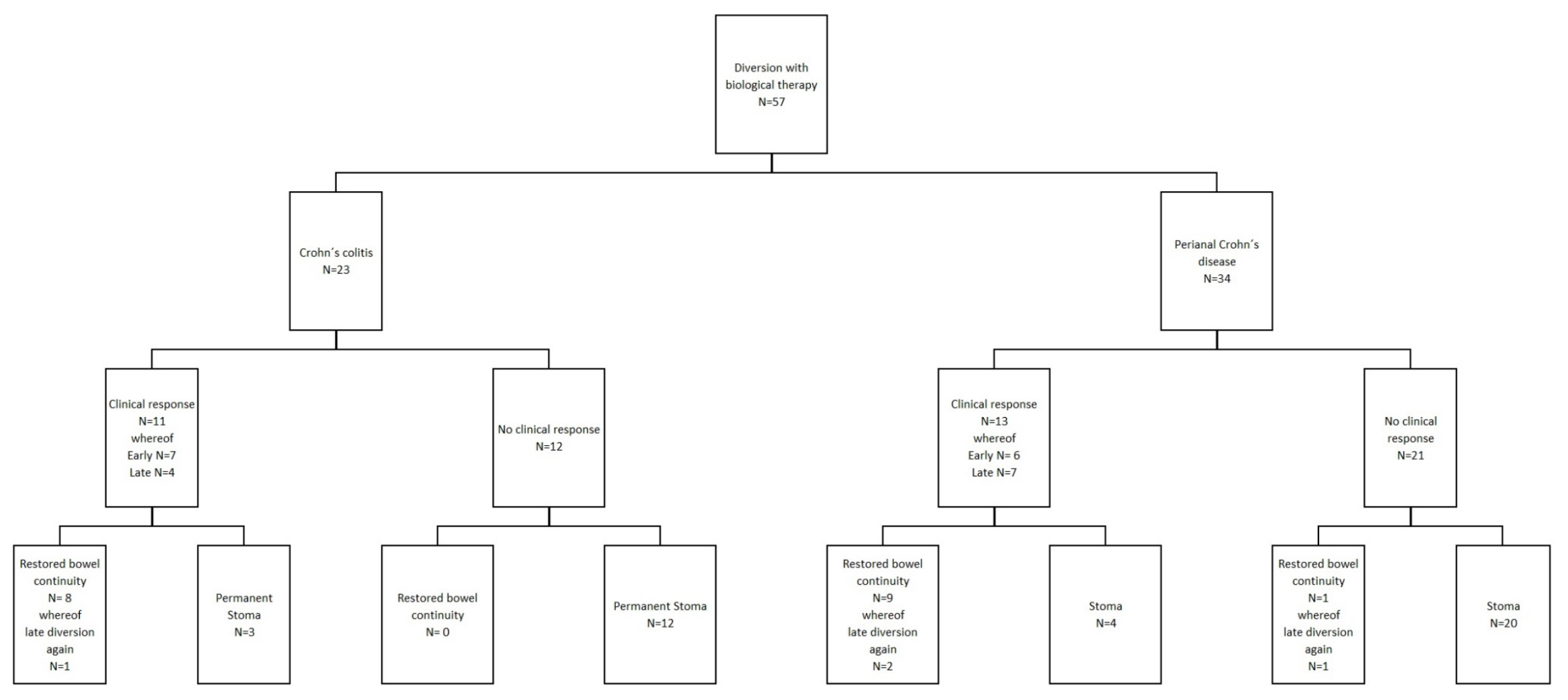


Fig 1 B

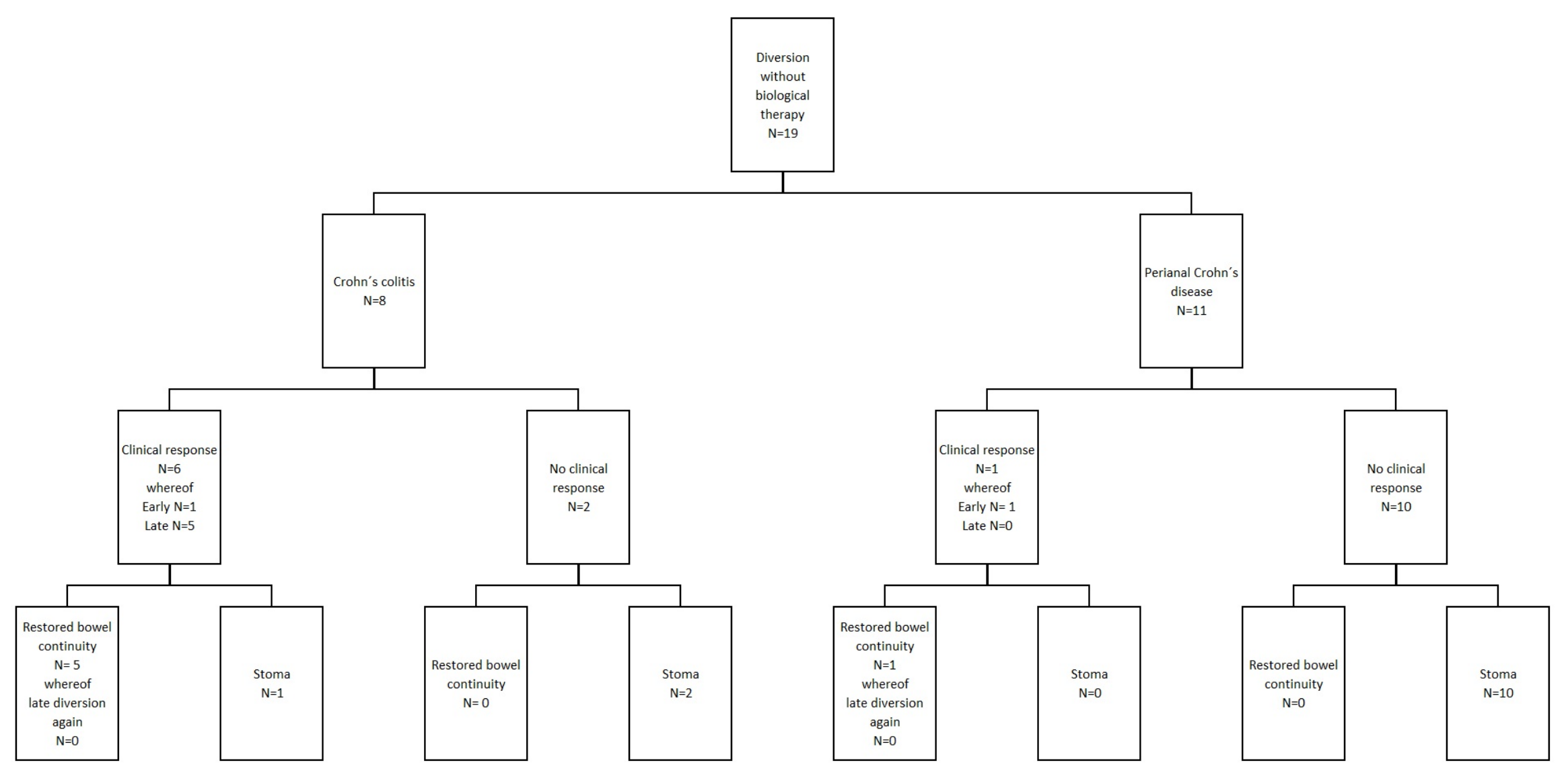


Figure 2

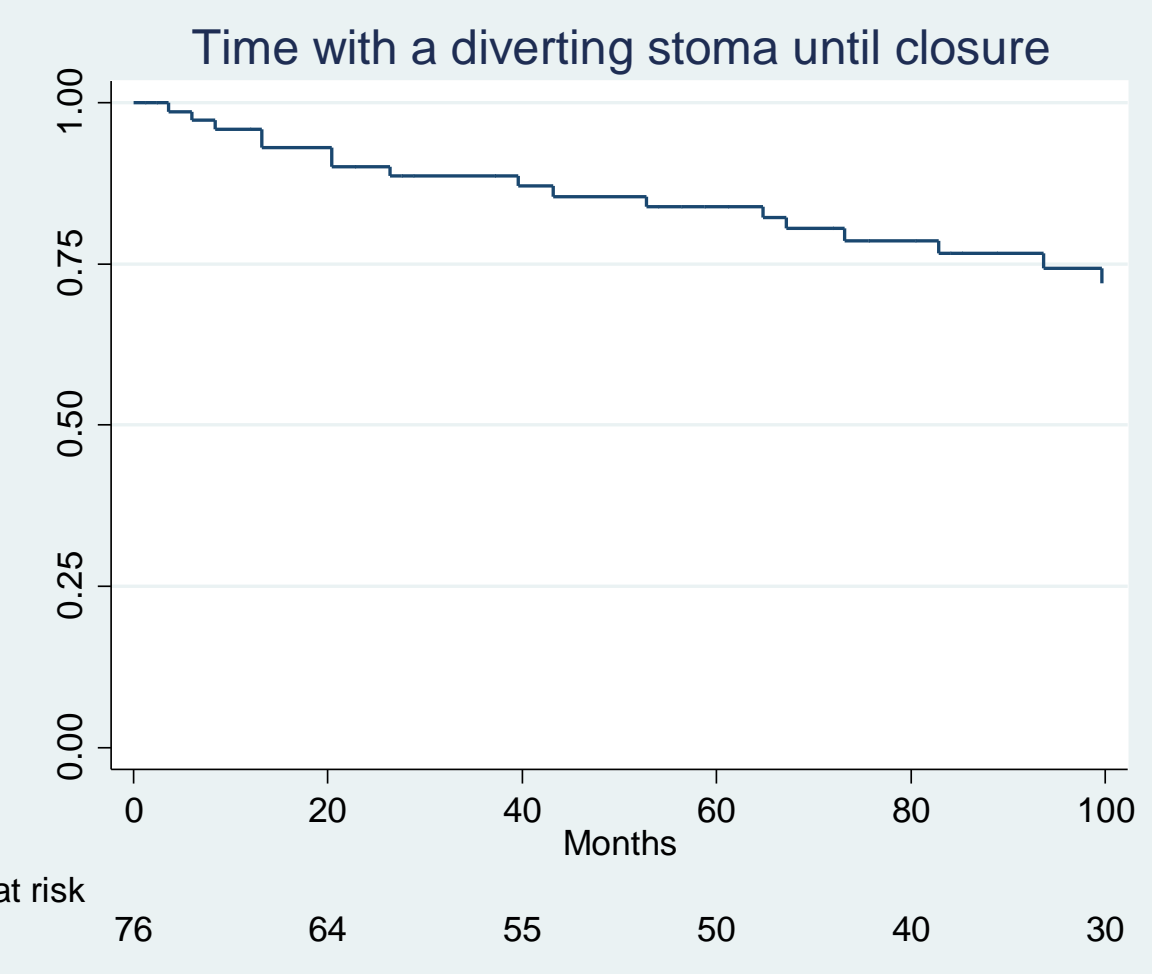


Figure 3

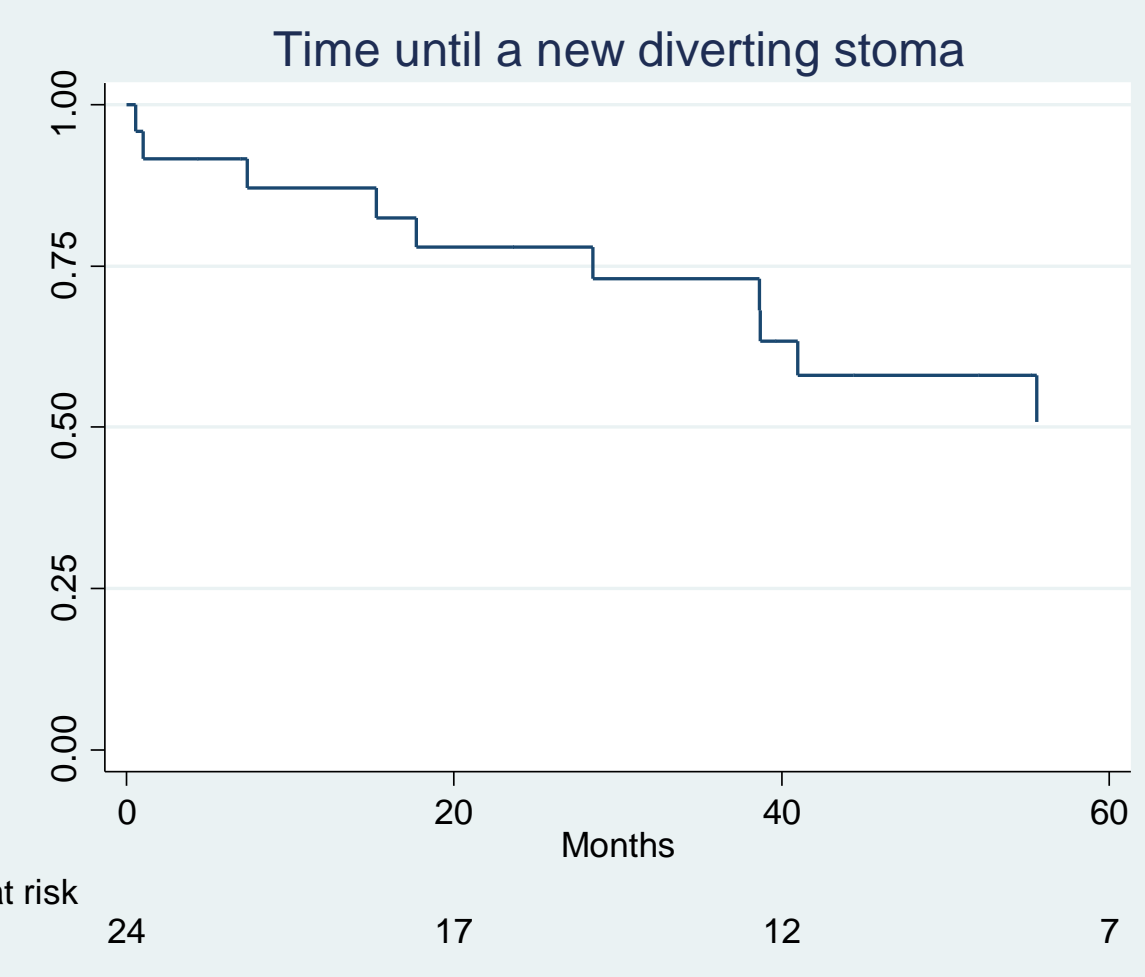

